\title{
Role of NO in the pulmonary artery hyporeactivity to phenylephrine in experimental biliary cirrhosis
}

\author{
F. Chabot*, H. Mestiri, S. Sabry, J. Dall'Ava-Santucci, A. Lockhart, A.T. Dinh-Xuan
}

Role of NO in the pulmonary artery hyporeactivity to phenylephrine in experimental biliary cirrhosis. F. Chabot, H. Mestiri, S. Sabry, J. Dall'Ava-Santucci, A. Lockhart, A.T. Dinh-Xuan. CERS Journals Ltd 1996.

ABSTRACT: The aim of this study was to see whether increased activity of nitric oxide (NO) might account for decreased pulmonary vascular tone seen in the hyperdynamic circulation of cirrhosis. We compared the pulmonary vascular reactivity of isolated pulmonary arteries (PA) from control rats $(n=10)$, and rats with biliary cirrhosis $(n=10)$ induced by chronic bile duct ligation ( 4 weeks).

The responses of PA rings to cumulative concentrations of phenylephrine, acetylcholine and sodium nitroprusside were studied, and also the effects of inhibition of synthesis of $\mathrm{NO}$ by the L-arginine analogue, $\mathrm{N}^{\omega}$-nitro-L-arginine (L-NOARG) in PA rings challenged with cumulative concentrations of phenylephrine and acetylcholine.

The contractile response to phenylephrine was significantly reduced in cirrhotic PA rings as compared with controls. Pretreatment with L-NOARG $\left(1^{-4} \mathrm{M}\right)$ significantly increased the contractile response to phenylephrine in PA rings from cirrhotic rats but not in control PA rings. Furthermore, L-NOARG restored the response to phenylephrine in cirrhotic PA rings back to normal. There was no difference in the relaxation of PA rings from both groups in response to acetylcholine and sodium nitroprusside.

We conclude that in vitro pulmonary artery ring hyporeactivity to phenylephrine results from increased nitric oxide production in the pulmonary circulation of cirrhotic rats and might account for the hepatopulmonary syndrome.

Eur Respir J., 1996, 9, 560-564
Service de Physiologie-Explorations Fonctionnelles, C.H.U. Cochin Port-Royal, Université René Descartes, Paris, France.

*Present address: Service des Maladies Respiratoires et Réanimation Respiratoire, C.H.U. Nancy-Brabois, rue du Morvan, 54511 Vandœuvre-les-Nancy, France.

Correspondence: A.T. Dinh-Xuan

Service de Physiologie-Explorations Fonctionnelles

Hôpital Cochin 27

rue du fg Saint-Jacques

75679 Paris cedex 14

France

Keywords: Cirrhosis

endothelium

nitric oxide

pulmonary vascular reactivity

Received: June 21995

Accepted after revision December 121995
Pulmonary vascular reactivity is often altered in cirrhosis resulting in the hepatopulmonary syndrome or, less frequently, pulmonary hypertension. The mechanisms underlying pulmonary hypertension in cirrhosis are still unknown [1]. However, it seems likely that they are different from those of the hepatopulmonary syndrome [2]. The latter is characterized by pulmonary gas exchange abnormalities with impaired hypoxic pulmonary vasoconstriction, intrapulmonary microvascular dilatation, high cardiac output and low pulmonary vascular resistance [2].

A recent hypothesis by VAllance and Moncada [3] related the hyperdynamic circulation in cirrhosis to increased synthesis and/or release of nitric oxide (NO). NO modulates pulmonary vascular tone in man both in health and disease [4, 5]. However, some uncertainties still exist as to the role of NO in the modulation of pulmonary vascular tone in rats [6-12].

Until the present time, only a few studies have looked at the putative role of NO in the hepatopulmonary syndrome. Mayoral et al. [13] found increased NO in the exhaled breath of patients with the hepatopulmonary syndrome, probably as a result of overproduction of NO in the lungs. However, there is so far no direct evidence supporting the hypothesis that NO production might be increased in the pulmonary circulation of patients with cirrhosis. Such evidence is difficult to obtain in humans. Therefore, we used an animal model of hepatopulmonary syndrome [14] to assess the reactivity of isolated pulmonary arteries from rats with biliary cirrhosis.

\section{Methods}

\section{Surgical techniques}

Male Sprague-Dawley rats weighing 150-175 g were purchased (Centre d'Elevage Janvier, Le Genest-SaintIsle, France) and given food and water ad libitum. They were divided into two groups. One group (cirrhosis group) had the common bile duct ligated, as described previously $[14,15]$. Briefly, under light ether anaesthesia, the abdomen was opened through a midline incision and the common bile duct was dissected and resected between 4.0 silk ligatures. The abdomen was closed with sutures and the rats were allowed to recover. The total mortality rate was approximately $20 \%$, with the majority of deaths in the first 2 weeks. This procedure is known to lead to biliary cirrhosis within 4 weeks with 
haemodynamic features of portal hypertension and hyperkinetic circulation with high cardiac output and decreased systemic vascular resistance $[14,15]$.

Histological features of liver cirrhosis were sought and documented in the first rats that underwent common bile duct ligation. In the control group, rats were anaesthetized and their abdomen was opened without bile duct ligature. Four weeks after the first operation, the heart-lung block was removed under ether anaesthesia for pharmacological study.

\section{Tissue preparation}

Segments of pulmonary artery were obtained from 20 rats (10 control and 10 with cirrhosis). Immediately after excision of the heart-lung block, tissues were placed in cold $\left(4^{\circ} \mathrm{C}\right)$, pregassed Krebs-Ringer bicarbonate (KR) solution and transported to the laboratory for dissection. The composition of the KR solution was as follows (in $\left.\mathrm{mmol} \cdot \mathrm{L}^{-1}\right): \mathrm{NaCl} 118 ; \mathrm{NaHCO}_{3} 25.5 ; \mathrm{KCl}$ 5.9; $\mathrm{NaHPO}_{4}$ 1.2; $\mathrm{MgSO}_{4}$ 1.2; $\mathrm{CaCl}_{2} 2.5$; glucose 5.6. Vascular segments were obtained from proximal pulmonary arteries which had been carefully dissected, cleaned of excessive connective tissue and cut into rings $(3-5 \mathrm{~mm}$ in length and 1-2 mm outer diameter). The endothelium was carefully preserved in all specimens.

Due to the relatively small size of the pulmonary circulation of the rat, the tissue obtained from each animal could only be divided into 2-4 different vascular segments, each segment being tested only once. Because this study involved the testing of various pharmacological compounds (see next paragraph), the number of rats used for a given subset of pharmacological study was always less than 10, which represented the total number of rats in the control and the disease groups, respectively.

\section{Pharmacological studies}

Dose-contraction studies. Rings were mounted over fine rigid wires, in organ chambers filled with $13 \mathrm{~mL}$ of KR buffer, which was freshly prepared. The solution was bubbled with $95 \% \mathrm{O}_{2}$ and $5 \% \mathrm{CO}_{2}$, maintained at $37^{\circ} \mathrm{C}$ by an outer bath warmed by a recirculating heater (Polystat 22, Biobkock, Illkirch, France). Each ring was preset at its optimal length for tension development, and changes in isometric tension were recorded by a force transducer (Amplifier 6112, Palmer Bioscience, Sheerness, UK) connected to a chart drive recorder (L 6514, Linseis, Bioblock, Illkirch, France). After precontraction with potassium chloride $(\mathrm{KCl}, 60 \mathrm{mM})$, the rings were carefully washed, and were allowed to equilibrate in the bath with the tension returning to baseline, at least 60 min during which the fluid in the bath, was changed every $15 \mathrm{~min}$. After equilibration, all rings were preincubated for $30 \mathrm{~min}$ with indomethacin $\left(10^{-5} \mathrm{M}\right)$, which remained in the bath throughout the studies. Thereafter, contraction to cumulative doses of L-phenylephrine dichloride $\left(10^{-8}\right.$ to $10^{-5}$ $\mathrm{M})$ was assessed. To assess the influence of NO on the vasocontractile response to phenylephrine, some of the rings were pretreated with a competitive inhibitor of $\mathrm{NO}$ synthesis, the L-arginine analogue, $\mathrm{N}^{\omega}$-nitro-L-arginine (L-NOARG, $10^{-4} \mathrm{M}$ ).

Dose-relaxation studies. After submaximal precontraction with phenylephrine to obtain a stable plateau of increased tension, cumulative concentrations of acetylcholine chloride $\left(10^{-8}\right.$ to $\left.10^{-5} \mathrm{M}\right)$ and sodium nitroprusside $\left(10^{-8}\right.$ to $\left.10^{-4} \mathrm{M}\right)$ were added to the baths to assess endothelium-dependent and -independent vasodilatation, respectively, in PA rings from both groups.

\section{Drugs}

All the drugs were purchased from Sigma Chemical (Saint-Quentin Fallavier, France) and diluted in distilled water, except for indomethacin, which was dissolved in $50 \%$ ethanol. The final concentration of ethanol in the organ bath did not exceed $0.001 \%$, which, in itself, did not have any effect on the tissue. All solutions were freshly prepared before use.

\section{Statistical analysis}

All data were expressed as mean \pm SEM. Contraction in response to phenylephrine was expressed as the percentage of contraction in response to $\mathrm{KCl}(60 \mathrm{mM})$. Relaxation in response to acetylcholine and sodium nitroprusside was expressed as the percentage of precontraction. Nonparametric Wilcoxon test for unpaired values [16] was used to compare reactivity (i.e. maximal contraction and maximal relaxation) of PA rings from cirrhotic rats and controls in response to phenylephrine, acetylcholine and sodium nitroprusside. Response of PA rings pretreated with L-NOARG was compared with those of untreated PA rings from both the control and the cirrhotic groups by the nonparametric Wilcoxon test for paired values [16]. A p-value of less than 0.05 was considered to indicate statistical significance.

\section{Results}

All rats were studied 28 days after bile duct ligation or sham-operation. Histologically, livers of rats with chronic bile duct ligation showed evidence of micronodular cirrhosis with severe fibrosis.

PA rings from rats with cirrhosis developed a lesser vasocontractile response to phenylephrine as compared with controls (maximal contraction $=123 \pm 9 \%$ in control rats versus $93 \pm 11 \%$ in rats with cirrhosis; $\mathrm{p}<0.01$ ) (fig. 1 ). Pretreatment with L-NOARG restored the vasocontractile response to phenylephrine in PA rings of cirrhotic rats (increasing maximal contraction from $93 \pm 11$ to $127 \pm$ $15 \%$; $<<0.005$ ) (fig. 2). L-NOARG did not significantly change the vasocontractile response to phenylephrine in $P A$ rings of control rats (maximal contraction $=128 \pm 25$ versus $123 \pm 9 \%$ in PA rings pretreated and untreated with LNOARG, respectively) (fig. 2). There was no significant 


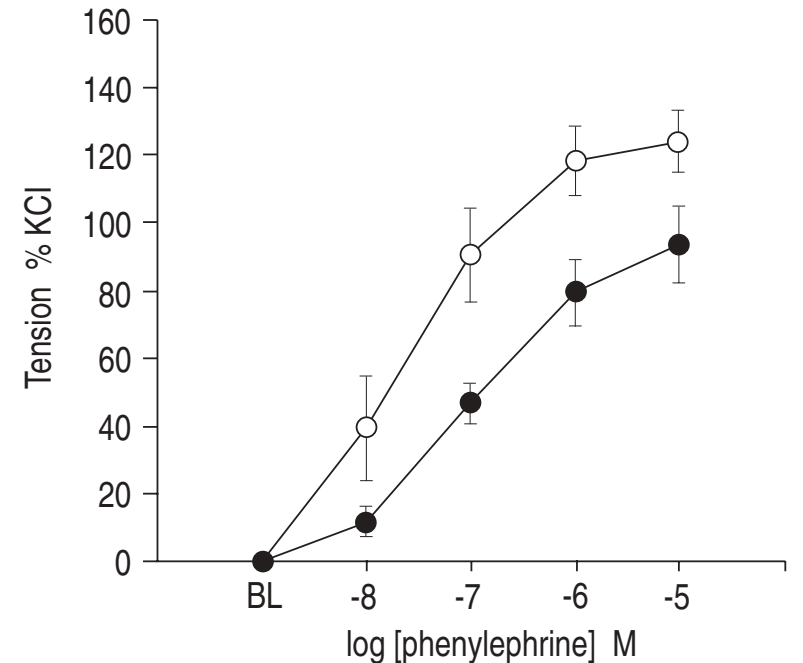

Fig. 1. - Tension developed in response to phenylephrine in pulmonary arterial rings from control rats $(n=7)(-\bigcirc-)$ and cirrhotic rats $(n=5)(--)$ expressed as \% of tension developed to KCI. Results are expressed as mean \pm SEM. Each ring was obtained from a different animal. BL: baseline.

difference between the rings of cirrhotic rats after addition of L-NOARG compared to those of control rats after addition of L-NOARG (fig. 2).

Acetylcholine induced a similar relaxation in both groups (fig. 3). Pretreatment with L-NOARG significantly inhibited endothelium-dependent relaxation to acetylcholine $(\mathrm{p}<0.0001)$ in pulmonary artery rings from rats of both groups (fig. 3). There was no significant difference between the groups in the concentration-dependent relaxation to sodium nitroprusside (fig. 4).

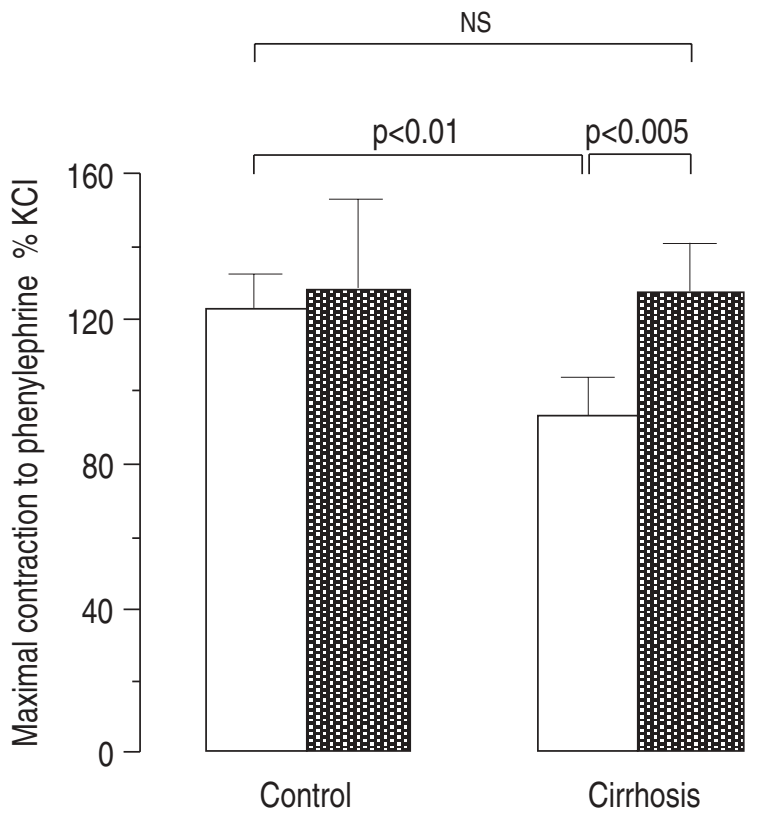

Fig. 2. - Maximal contraction developed in response to phenylephrine in rings from control $(n=7)$ and cirrhotic rats $(n=5)$. The rings are divided into two groups as follows: untreated ( $\square$ ), treated with $\mathrm{N}^{\omega}$-nitro-L-arginine ( nonsignificant.

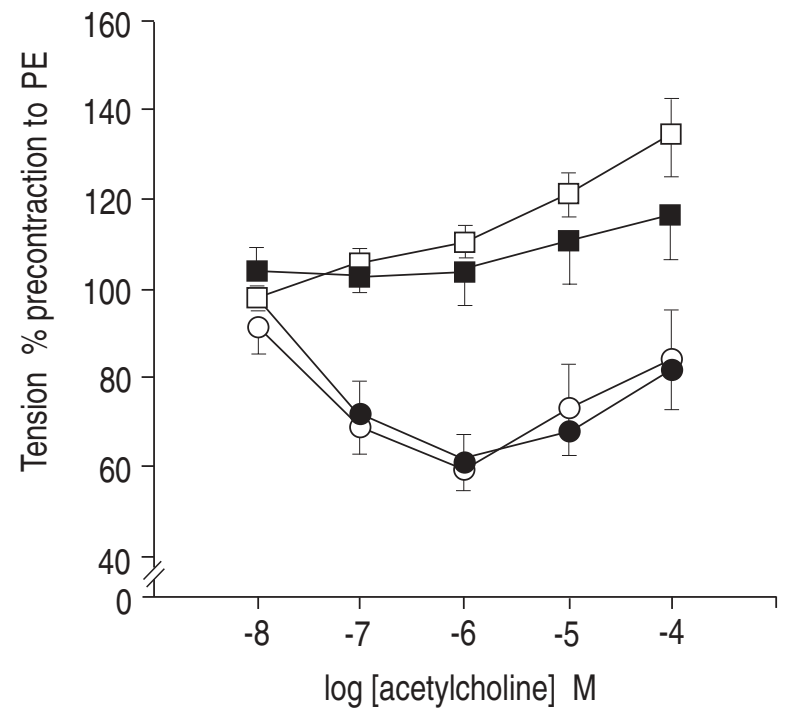

Fig. 3. - Endothelium-dependent relaxation to cumulative doses of acetylcholine in pulmonary arterial rings from control (open symbols) and cirrhotic (closed symbols) rats. The rings are divided into two groups as follows: untreated (circles), treated with $\mathrm{N}^{\omega}$-nitro-L-arginine (squares). The reduced tension is expressed as \% of submaximal precontraction to phenylephrine (PE). Results are expressed as mean \pm SEM. For all groups $n=8$.

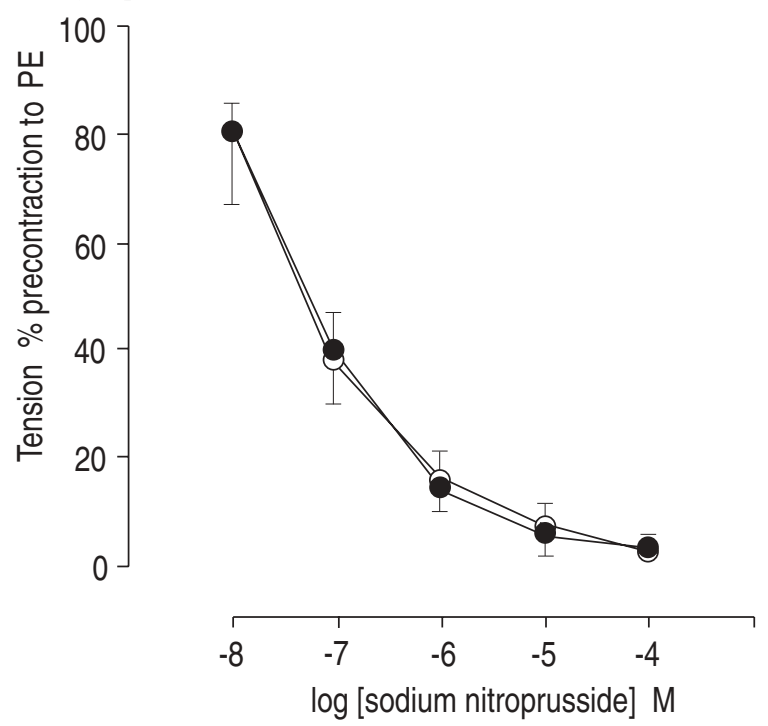

Fig. 4. - Endothelium-independent relaxation to cumulative doses of sodium nitroprusside in pulmonary arterial rings from control (open symbols) and cirrhotic (closed symbols) rats. The reduced tension is expressed as \% of submaximal precontraction to phenylephrine. Results are expressed as mean \pm SEM. Each ring was obtained from a different animal. For both groups $n=7$.

\section{Discussion}

The main results of this study indicate that pulmonary artery rings from cirrhotic rats developed less vasocontractile response to phenylephrine than controls. Such pulmonary vascular hyporeactivity probably results from NO overproduction, as it was abolished by inhibition of NO synthesis by the L-arginine analogue, L-NOARG.

Ligation and excision of the common bile duct in rats induce an extrahepatic cholestasis with histologic features of biliary cirrhosis 4 weeks later [14], as was confirmed in our study. We did not perform cardiorespiratory measurements to characterize the pulmonary and systemic 
haemodynamic state of these animals because it has been established that awake rats with chronic bile duct ligation develop many features of human cirrhosis, including hyperdynamic circulation, low pulmonary vascular resistance, impaired pulmonary gas exchange and depressed hypoxic pulmonary vasoconstriction $[14,15]$. Rats with chronic bile duct ligation, therefore, present with the hallmarks of the hepatopulmonary syndrome $[14,15]$. They can be reasonably considered as a fair model for the study of pulmonary circulatory changes in human cirrhosis.

Results of other studies investigating the effects of acute alveolar hypoxia are conflicting. In humans with cirrhosis, loss of hypoxic pulmonary vasoconstriction was observed by some investigators [17]. However, others have found that the hypoxic pulmonary vasoconstriction was at least partially preserved $[18,19]$. In rats with cirrhosis, CHANG and OHARA [14] observed a marked reduction of the vasopressor response to hypoxia, whereas pulmonary vasoconstrictor response to angiotensin II was preserved.

The underlying mechanisms of the hepatopulmonary syndrome are not well understood. One of the current hypotheses favours an abnormal sensitivity of the pulmonary vascular bed to a substance which is normally present in the pulmonary circulation. Alternatively, failure of inactivation, or production, of circulating vasoactive substances by the liver, leading to altered pulmonary vasoreactivity are also likely to account for the hepatopulmonary syndrome [2].

Among vasodilator substances, $\mathrm{NO}$ is likely to play an important role [3]. L-arginine analogues, such as $\mathrm{NG}_{-}$ monomethyl-L-arginine (L-NMMA) and L-NOARG, are useful pharmacological tools in the study of the L-arginine-NO pathway [20]. Recent studies suggest that other NO synthase inhibitors could be more specific for either the constitutive $[21,22]$ or inducible $[23,24]$ isoforms. However, at the time of the present study, L-NOARG was chosen because it was known to be more potent than L-NMMA in inhibiting NO synthesis [25]. L-NOARG restored the vasocontractile response to phenylephrine in pulmonary artery rings from cirrhotic rats. These results suggest that overproduction of NO is, at least in part, responsible for decreased response to vasoconstrictor stimuli of the pulmonary vascular bed in cirrhosis. This, in turn, could favour excessive pulmonary vasodilatation or impaired hypoxic pulmonary vasoconstriction as seen in the hepatopulmonary syndrome.

Consistent with our in vitro results, are the recent findings by MAYORAL et al. [13], who measured NO in the exhaled gas of patients with hepatopulmonary syndrome. Compared with normoxaemic cirrhotics and healthy volunteers, exhaled NO was increased in these patients. Furthermore, methylene blue, which blocks NO activity, has been reported to decrease pulmonary shunting in one patient [26]. Our observations in isolated pulmonary artery, together with these recent reports [13, 26] are consistent with the hypothesis that increased NO production may account for the pulmonary haemodynamic changes in the hepatopulmonary syndrome. Experimental results obtained in the systemic and splanchnic circulation are also consistent with the hypothesis of increased NO production as the cause of arterial hypotension and splanchnic vasodilatation of rats with cirrhosis or portal hypertension [27-31].

There was no difference in the vasodilator response to acetylcholine and sodium nitroprusside in pulmonary artery rings of cirrhotic rats as compared with controls. The endothelium-dependent vasodilator, acetylcholine, induces the release of NO, by stimulating the constitutive form of the NO synthase through activation of endothelial muscarinic receptors [20]. However, acetylcholine also causes the release of the so-called endotheliumderived hyperpolarizing factor, which might differ from NO [32]. Due to the coexistence of these different pathways through which acetylcholine causes vasorelaxation, it seems difficult to draw any firm conclusion from the present data. Nevertheless, the lack of difference in acetylcholine-induced vasodilatation does not favour the hypothesis of increased activity of the constitutive NO synthase in cirrhosis. Therefore, NO overproduction in the lung of cirrhotic rats is probably the result of increased activity of the inducible NO synthase, as suggested by VAllance and Moncada [3].

The endothelium-independent vasodilator sodium nitroprusside relaxes smooth muscle by activating the soluble form of the enzyme guanylate cyclase which, in turn, gives rise to the second messenger cyclic guanosine monophosphate (cGMP) [33]. In contrast to acetylcholine, sodium nitroprusside induces vasorelaxation after its conversion to NO without requiring the presence of endothelium. The lack of difference in response to sodium nitroprusside between cirrhotic and control rats suggest that the soluble guanylate cyclase-cGMP pathway is not altered in pulmonary vascular smooth muscle in cirrhosis.

The importance of NO as a modulator of vascular tone in the pulmonary vascular bed of normal rats is still debated. Various inhibitors of NO synthesis or activity have been shown to increase normoxic and hypoxic pulmonary vasomotor tone in some but not all experiments [6-12]. In this study, pretreatment by L-NOARG did not significantly increase the vasocontractile response to phenylephrine in pulmonary artery rings from control rats. Our results suggest that background production of NO is not important in the modulation of increased tone to phenylephrine in the conduit pulmonary artery of normal rats. This is supported by the recent study of ISAACSON et al. [12], who found a low concentration of NO oxidation products in the effluent of isolated rat lung.

In summary, this study demonstrates that pulmonary artery rings of cirrhotic rats developed hyporeactivity in response to phenylephrine in vitro as a result of an increased production of NO in the pulmonary circulation.

\section{References}

1. Harris P, Heath D. Portal and pulmonary hypertension. In: Harris $\mathrm{P}$, Heath $\mathrm{D}$, eds. The Human Pulmonary Circulation: Its Form and Function in Health and Disease. Edinburgh, Churchill Livingstone, 1986; 444-455. 
2. Rodriguez-Roisin R, Agustí AGN, Roca J. The hepatopulmonary syndrome: new name, old complexities. Thorax 1992; 47: 897-902.

3. Vallance P, Moncada S. Hyperdynamic circulation in cirrhosis: a role for nitric oxide? Lancet 1991; 337: 776-778.

4. Dinh-Xuan AT, Higenbottam TW, Clelland CA, et al. Impairment of endothelium-dependent pulmonary artery relaxation in chronic obstructive lung disease. $N$ Engl $J$ Med 1991; 324: 1539-1547.

5. Dinh-Xuan AT. Disorders of endothelium-dependent relaxation in pulmonary disease. Circulation 1993; 87 (Suppl. 5): V81-V87.

6. Brashers VL, Peach MJ, Rose CE Jr. Augmentation of hypoxic pulmonary vasoconstriction in the isolated perfused rat lung by in vitro antagonists of endotheliumdependent relaxation. J Clin Invest 1988; 82: 1495-1502.

7. Hasunuma K, Yamaguchi T, Rodman DM, O'Brien RF, McMurtry IF. Effects of inhibitors of EDRF and EDHF on vasoreactivity of perfused rat lungs. Am J Physiol 1991; 260: L97-L104.

8. Liu SF, Crawley DE, Barnes PJ, Evans TW. Endotheliumderived relaxing factor inhibits hypoxic pulmonary vasoconstriction in rats. Am Rev Respir Dis 1991; 143: 32-37.

9. Adnot S, Raffestin B, Eddahibi S, Braquet P, Chabrier PE. Loss of endothelium-dependent relaxant activity in the pulmonary circulation of rats exposed to chronic hypoxia. J Clin Invest 1991; 87: 155-162.

10. Barnard JW, Wilson PS, Moore TM, Thompson WJ, Taylor AE. Effect of nitric oxide and cyclo-oxygenase products on vascular resistance in dog and rat lungs. $J$ Appl Physiol 1993; 74: 2940-2948.

11. Hampl V, Archer SL, Nelson DP, Weir EK. Chronic EDRF inhibition and hypoxia: effects on pulmonary circulation and systemic blood pressure. J Appl Physiol 1993; 75: 1748-1757.

12. Isaacson TC, Hampl V, Weir EK, Nelson DP, Archer SL. Increased endothelium-derived NO in hypertensive pulmonary circulation of chronically hypoxic rats. $J$ Appl Physiol 1994; 76: 933-940.

13. Mayoral V, Higenbottam TW, Cremona G, Alexander G, Borland CDR, Jones G. Exhaled nitric oxide is elevated in patients with hepatopulmonary syndrome $(\mathrm{Ab}-$ stract). Am J Respir Crit Care Med 1994; 149: A26.

14. Chang SW, Ohara N. Pulmonary circulatory dysfunction in rats with biliary cirrhosis: an animal model of the hepatopulmonary syndrome. Am Rev Respir Dis 1992; 145: 795-805.

15. Lee SS, Girod C, Braillon A, Hadengue A, Lebrec D. Hemodynamic characterization of chronic bile ductligated rats: effect of pentobarbital sodium. Am J Physiol 1986; 251: G176-G180.

16. Zar JH. Biostatistical analysis, 2nd edn. Prentice Hall, Englewood Cliffs, 1984.

17. Daoud FS, Reeves JT, Schaefer JW. Failure of hypoxic pulmonary vasoconstriction in patients with liver cirrhosis. J Clin Invest 1972; 51: 1076-1080.
18. Naeije R, Hallemans R, Mols P, Mélot C. Hypoxic pulmonary vasoconstriction in liver cirrhosis. Chest 1981; 80: $570-574$.

19. Rodriguez-Roisin R, Roca J, Agustí AGN, Mastai R, Wagner PD, Bosch J. Gas exchange and pulmonary vascular reactivity in patients with liver cirrhosis. Am Rev Respir Dis 1987; 135: 1085-1092.

20. Moncada S, Palmer RMJ, Higgs EA. Nitric oxide: physiology, pathophysiology and pharmacology. Pharmacol Rev 1991; 43: 109-142.

21. Schini VB, Vanhoutte PM. Inhibitors of calmodulin impair the constitutive but not the inducible nitric oxide synthase activity in the rat aorta. J Pharmacol Exp Ther 1992; 261: 553-559.

22. Zembowicz A, Hatchett RJ, Radziszewski W, Gryglewski RJ. Inhibition of endothelial nitric oxide synthase by ebselen: prevention by thiols suggests the inactivation by ebselen of a critical thiol essential for the catalytic activity of nitric oxide synthase. J Pharmacol Exp Ther 1993; 267: 1112-1118.

23. Yu SM. Thaliporphine selectively inhibits expression of the inducible, but not the constitutive, nitric oxide synthase. Biochem J 1994; 303: 289-294.

24. Wolff DJ, Lubeskie A. Aminoguanidine is an isoformselective, mechanism-based inactivator of nitric oxide synthesis. Arch Biochem Biophys 1995; 316: 290-301.

25. Moore PK, al Swayeh OA, Chong NWS, Evans RA,

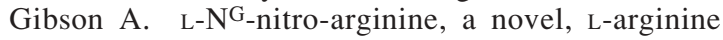
reversible inhibitor of endothelium-dependent vasodilatation in vitro. Br J Pharmacol 1990; 99: 408-412.

26. Rolla G, Bucca C, Brussino L. Methylene blue in the hepatopulmonary syndrome (Letter). N Engl J Med 1994; 331: 1098.

27. Pizcueta MP, Pique JM, Bosch J, Whittle BJR, Moncada S. Effects of inhibiting nitric oxide biosynthesis on the systemic and splanchnic circulation of rats with portal hypertension. Br J Pharmacol 1992; 105: 184-190.

28. Lee FY, Albillos A, Colombato LA, Groszmann RJ. The role of nitric oxide in the vascular hyporesponsiveness to methoxamine in portal hypertensive rats. Hepatology 1992; 16: 1043-1048.

29. Sieber CC, Groszmann RJ. In vitro hyporeactivity to methoxamine in portal hypertensive rats: reversal by nitric oxide blockade. Am J Physiol 1992; 262: G996G1001.

30. Claria J, Jimenez W, Ros J, et al. Pathogenesis of arterial hypotension in cirrhotic rats with ascites: role of endogenous nitric oxide. Hepatology 1992; 15: 343-349.

31. Castro A, Jimenez W, Claria J, et al. Impaired responsiveness to angiotensin II in experimental cirrhosis: role of nitric oxide. Hepatology 1993; 18: 367-372.

32. Taylor SG, Weston AH. Endothelium-derived hyperpolarizing factor: a new endogenous inhibitor from the vascular endothelium. Trends Pharmacol Sci 1988; 9: 272-274.

33. Murad F. Cyclic guanosine monophosphate as a mediator of vasodilatation. J Clin Invest 1986; 78: 1-5. 